\title{
Five years of Alpine Entomology, the international journal on mountain insects
}

\author{
Thibault Lachat ${ }^{1,2}$, Oliver Y. Martin ${ }^{3}$ \\ 1 Editor in Chief, Bern University of Applied Sciences, Zollikofen, Switzerland \\ 2 Swiss Federal Institute for Forest, Snow and Landscape Research, Birmensdorf, Switzerland \\ 3 President of the Swiss Entomological Society and member of the editorial board, Department of Biology \& Institute of Integrative Biology, \\ ETH Zürich, Switzerland \\ http://zoobank.org/102545FC-A303-4328-88C0-B2BB2022032F
}

Corresponding author: Thibault Lachat (thibault.lachat@bfh.ch)

Published 22 November 2021

With this new issue, our journal Alpine Entomology celebrates its $5^{\text {th }}$ anniversary. From the very beginning, it was clear for the Swiss Entomological Society that our journal would not solely focus on insects from the Alps. Alpine Entomology should be very much perceived as an international journal for mountain entomology worldwide. At first sight, the term mountain seems to be simple to define. Nevertheless, in reality, these rugged structures in the landscape are not that easy to delineate, and mountains can be defined in different ways (see e.g., Körner et al. 2021). For this reason, when we evaluate each manuscript submitted, we also consider the landscape and taxonomic context of the study. It is important to note that our journal is not restricted to insects, because articles focusing on other mountain arthropods are also welcome. In summary, Alpine Entomology publishes articles on all aspects of arthropods from the Alpine region and other mountainous regions all over the world.

Similar to many other species groups, insects are affected by the biodiversity crisis caused by land use and climate changes, over or under use of resources, pollution, and invasive alien species (IPBES 2019). After the famous Krefeld study, which highlighted a loss of $75 \%$ of the insect biomass over the last 27 years in protected areas in Germany (Hallmann et al. 2017), further scientific articles and reviews have been published on this topic (e.g., Seibold et al. 2019; Wagner 2020). Nowadays, it is obvious, that the diversity and biomass of insects are strongly threatened globally. Nevertheless, not all insect populations are decreasing. Some thermophilous species can benefit from climate change and hence expand their population size and their distribution (e.g., Roth et al.
2021). There are also examples of increasing insect populations due to successful conservation measures (e.g., Walter et al. 2017).

A comprehensive recent study published in a Swiss Academic Report (Widmer et al. 2021) concluded that conservation measures are urgently needed to avoid dramatic losses of insects and the valuable ecosystem services they provide. This is necessary for all activity sectors such as agriculture, forestry, and energy production. Among other measures, this report recommends an intensification of species monitoring and research activities in entomology, and an improvement in knowledge transfer. Our journal, Alpine Entomolo$g y$, fulfills this goal extremely well. As an open-access journal, we aim at publishing inter alia research and review articles, short communications and checklists on arthropods not only from the Alps but also from other mountainous regions. In doing so, we contribute to the dissemination of knowledge on insects to a broad audience. For example, more than twenty articles published in Alpine Entomology since 2017 have acquired more than 2'000 unique views.

To improve the international impact and scientific quality of Alpine Entomology, we can now count on our recently formed editorial board. The board members will act as ambassadors for our journal outside of Switzerland, as well as support us in our strategic decisions.

Our Editorial board is currently composed of the following people:

Prof. Dr. Thibault Lachat, Editor in chief, Bern University of Applied Sciences 
Dr. Oliver Martin, President of the Swiss Entomological Society, ETH Zurich

Dr. Yves Basset, Smithsonian Tropical Research Institute, Panama

Prof. Dr. Inon Scharf, Tel Aviv University

PD Dr. Seraina Klopfstein, Natural History Museum, Basel

Prof. Dr. Lyubomir Penev, Managing Director and Founder of Pensoft Publishers

We are open to extending this board by inviting a few additional members, and especially hope to recruit international researchers working in regions not currently represented.

A few weeks ago, we launched our first topical collection, a step that should also help to increase the attractivity of our journal. This collection is focused on arthropods associated with aquatic ecosystems in mountainous regions.

Aquatic ecosystems and especially running waters represent some of the most impacted environments on the planet. Furthermore, aquatic invertebrates are key indicators of global or local changes, and many aquatic ecosystems are closely linked to mountains as they originate in them.

With this open collection, Alpine Entomology now provides authors with an opportunity to submit manuscripts based on already available data with clear evidence for changes/trends in aquatic arthropods (even where sampling designs were not initially conceived for this goal). Such studies would be highly relevant to improving our understanding of developments concerning arthropod populations and knowledge of aquatic species.

With this initiative, we aim to provide a platform for scientists to publish research articles or short notes on trends and/or changes in biogeography, species community or distribution, as well as behavior, or morphology of aquatic arthropods from mountainous regions. The editors of this collection (Jean-Luc Gattolliat and Dávid Murányi) will be inviting authors to submit their manuscript and will offer a fee waiver for invited contributions. The topical collection is also open to relevant additional contributions (for details see https://alpineentomology, pensoft.net/special issues).

Over the next months, we plan to launch further topical collections and therefore hope to offer attractive avenues for researchers to publish their results in our journal. The editorial board will be involved in evaluating suggestions for future topics, as well as recruiting new topics in a targeted fashion

After five years of existence, Alpine Entomology has already surmounted different challenges. Since 2019, our journal has been indexed in Emerging Sources Citation by
Clarivate Analytics and since 2020, we are also indexed by Scopus. One of our goals for the next years will be to obtain an impact factor from Clarivate. This would provide a clear signal that our journal is well established and recognized in the scientific community. To reach this goal, we need to recruit and secure a consistent flow of manuscripts aiming at ca. 20-25 published papers per year. Of course, the quality of our published articles must also be guaranteed. Fortunately, for this we can continue to count on the strong support of our expert subject editors and the numerous reviewers. Here, we would like to take the opportunity to thank all those involved for their essential contributions to our journal over the years since its creation.

\section{References}

Hallmann CA, Sorg M, Jongejans E, Siepel H, Hofland N, Schwan H, Stenmans W, Müller A, Sumser H, Hörren T, Goulson D, Kroon H de (2017) More than 75 percent decline over 27 years in total flying insect biomass in protected areas. PLoS ONE 12(10): e0185809. https://doi.org/10.1371/journal.pone.0185809

IPBES (2019) Global assessment report on biodiversity and ecosystem services of the Intergovernmental Science-Policy Platform on Biodiversity and Ecosystem Services. In: Brondizio ES, Settele J, Díaz S, Ngo HT (Eds) IPBES secretariat, Bonn, 1148 pp. https://doi. org/10.5281/zenodo.3831673

Körner C, Urbach D, Paulsen J (2021) Mountain definitions and their consequences. Alpine Botany 131:213-217. https://doi.org/10.1007/ s00035-021-00265-8

Roth T, Plattner M, Sartori L, Gonseth Y (2021) Tagfalter-Index: Kälteliebende Arten werden seltener: Ergebnisse aus den nationalen Monitoringprogrammen. Hotspot 43: 26-27.

Seibold S, Gossner MM, Simons NK, Blüthgen N, Müller J, Ambarlı D, Ammer C, Bauhus J, Fischer M, Habel JC, Linsenmair KE, Nauss T, Penone C, Prati D, Schall P, Schulze E-D, Vogt J, Wöllauer S, Weisser WW (2019) Arthropod decline in grasslands and forests is associated with landscape-level drivers. Nature 574: 671-674. https://doi. org/10.1038/s41586-019-1684-3

Wagner DL (2020) Insect Declines in the Anthropocene. Annual Review of Entomology 65: 457-480. https://doi.org/10.1146/annurev-ento-011019-025151

Walter T, Richner N, Meier E, Hoess R (2017) Laufkäfer in der AareAue Rupperswil, Kanton Aargau, in den ersten fünf Jahren nach der Renaturierung (Coleoptera, Carabidae). Alpine Entomology 1: 5-15. https://doi.org/10.3897/alpento.1.20948

Widmer I, Mühlethaler R, Baur B, Gonseth Y, Guntern J, Klaus G, Knop E, Lachat T, Moretti M, Pauli D, Pellissier L, Sattler T, Altermatt F (2021) Insektenvielfalt in der Schweiz: Bedeutung, Trends, Handlungsoptionen. Swiss Academies Reports 16, 108 pp. https://doi. org/10.5281/ZENODO.5144739 